\title{
ERRATUM
}

F. D. Fischer • J. Predan • O. Kolednik • N. K. Simha

\section{Application of material forces to fracture of inhomogeneous materials: illustrative examples}

Published online: 22 July 2008

(c) Springer-Verlag 2008

Erratum to: Arch Appl Mech (2007) 77:95-112

DOI 10.1007/s00419-006-0058-0

The authors detected a misprint in Eq. (7) which should correctly be written as

$$
\mathrm{J}_{\mathrm{far}}=2 \int_{\text {Path } 2} \phi \mathrm{d} s-2 \int_{\text {Path } 4} \phi \mathrm{d} s .
$$

All calculations in the text are not affected by this misprint.

The online version of the original article can be found under doi:10.1007/s00419-006-0058-0.

F. D. Fischer $(\varangle)$

Institute of Mechanics, Montanuniversität Leoben, Franz-Josef-Strasse 18, 8700 Leoben, Austria

E-mail: mechanik@unileoben.ac.at

Tel.: +43-3842-4024000

Fax: +43-3842-46048

F. D. Fischer · O. Kolednik

Materials Center Leoben, Franz-Josef-Strasse 13, 8700 Leoben, Austria

J. Predan

Faculty of Mechanical Engineering,

University of Maribor, Smetanova ulica 17, 2000 Maribor, Sm Slovenia

O. Kolednik

Erich Schmid Institute of Materials Science,

Austrian Academy of Sciences, Jahnstrasse 12, 8700 Leoben, Austria

N. K. Simha

Department of Orthopaedic Surgery, University of Minnesota,

MMC 289, 420 Delaware, St. SE, Minneapolis, MN 55455, USA 